\title{
A Novel Method for Rotor Field-Oriented Control of Single- Phase Induction Motor
}

\author{
M. Jannati*, T. Sutikno**, N.R.N. Idris*, M.J.A. Aziz* \\ * UTM-PROTON Future Drive Laboratory, Faculty of Electrical Engineering, Universiti Teknologi Malaysia, 81310 \\ Skudai, Johor Bahru, Malaysia \\ ** Department of Electrical Engineering, Universitas Ahmad Dahlan, Yogyakarta, Indonesia
}

\section{Article Info \\ Article history: \\ Received Dec 2, 2014 \\ Revised Jan 25, 2015 \\ Accepted Feb 9, 2015}

\section{Keyword:}

Drive system

MATLAB

Rotor field-oriented control

Single-phase induction motor

Transformation matrix

\begin{abstract}
This paper presents a novel rotor field-oriented control (RFOC) method for asymmetrical single-phase induction motor (SPIM). It is shown in this paper that by using a suitable transformation matrix (TM) for stator current variables, the asymmetrical equations of SPIM are transformed into symmetrical equations. Based on this similarity, a novel vector conrol technique for SPIM is presented. Performance of the proposed method is assessed using MATLAB/SIMULINK software. Simulation results showed the excellence speed and torque responses obtained using the proposed technique.
\end{abstract}

Copyright $(\mathbb{C} 2015$ Institute of Advanced Engineering and Science. All rights reserved.

\section{Corresponding Author:}

M. Jannati,

UTM-PROTON Future Drive Laboratory, Faculty of Electrical Engineering,

Universiti Teknologi Malaysia,

81310 Skudai, Johor Bahru, Malaysia.

Email: jannatim94@yahoo.com

\section{INTRODUCTION}

Single-phase induction motors (SPIMs) are broadly implemented in low-power applications such as sub fractional and fractional horsepower applications for their low-cost and substantial reliability. A SPIM is fundamentally an unbalanced IM since it is constructed with two asymmetrical stator windings (main and auxiliary windings) with a squirrel-cage rotor.

To effectively control the torque and/or speed, SPIM is normally fed by power electronics converters. Different topologies of power converter have been used for variable-speed drives of SPIM [1][5]. Two-leg, three-leg, and four-leg converters are the three most widely used converters for SPIM. In general, three-leg and four-leg converters are more efficient as well as produce less harmonic distortion than a two-leg converter [4]. However, since two-leg configuration is cost-effective than the three-leg and fourleg, this configuration has been assumed in this study. The configuration of the two-leg SPIM drive system is shown in Figure 1 [4].

Scalar control method is quite popular technique for speed control of SPIM drive [6]-[8]. This control strategy is simple, economical, and well implementable. However, this control strategy provides slow reaction to transient and cannot be considered as an appropriate control strategy. Nowadays, direct torque control (DTC) [9], [10] and field-oriented control (FOC) [3]-[5] and [11]-[21] techniques have been widely adopted for SPIM drives for applications that require high performance torque control. Correa et al. has proposed FOC strategy using positive-negative double sequence current controller [5]. Although the proposed method, eliminate the torque pulsation of the SPIM but this method is complex, due to the using many PI controllers. In [11], decoupling vector control method with maximum torque per ampere was 
proposed for vector control of SPIM. In [12]-[15], Stator FOC and Rotor FOC techniques for SPIM using feed forward decoupling controller have been presented. The presented control methods in [11]-[15] are extremely depends on variations of SPIM parameters. In [16]-[20], some methods for FOC of SPIM based on using transformation matrices (TMs) have been proposed. These methods are also depended on motor parameters.

In this paper it is shown that using suitable TM for stator current variables, the equations of the asymmetrical SPIM can be transformed into a structure of equations, which are similar to the 3-phase IM equations. Based on this, a novel and simple RFOC strategy for SPIM is developed and through simulation, is shown to give excellent dynamic performance. The remainder of this paper is organized as follows. The dq model of the SPIM is presented in section 2. In section 3, the main idea of proposed vector control for SPIM is discussed and subsequently a novel control strategy based on RFOC is presented. The effectiveness of the proposed method is verified and presented using MATLAB/SIMULINK software in section 4. Finally, conclusion is presented in section 5 .

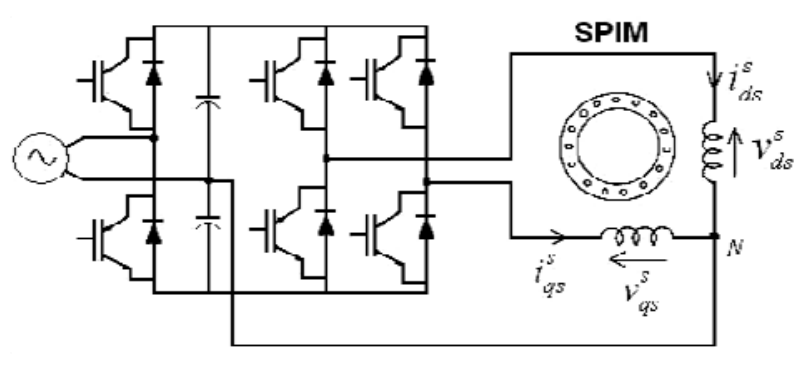

Figure 1. Configuration of the two-leg SPIM drive system

\section{MATHEMATICAL MODELING}

The SPIM equations in the stationary reference frame (superscript " $s$ ") can be written as (1) as presented in [5]:

$$
\begin{aligned}
& v_{t \mathrm{~L}}^{s}=r_{t \mathrm{~L}} i_{t \mathrm{~L}}^{s}+\begin{array}{c}
d \lambda_{d \mathrm{~L}}^{s} \\
d t
\end{array} \quad, \quad v_{q \mathrm{~s}}^{s}=r_{q \mathrm{~s}} i_{\mathrm{qS}}^{s}+\frac{d \lambda_{q s}^{s}}{d t} \\
& 0=r_{r} i_{d r}^{s}+\frac{d \lambda_{d r}^{s}}{d t}+\omega_{r} \lambda_{q r}^{s}, 0=r_{r} i_{q r}^{s}+\frac{d \lambda_{q r}^{s}}{d t}-\omega_{r} \lambda_{d r}^{s} \\
& \lambda_{d s}^{s}=L_{d s} i_{d s}^{s}+M_{d} i_{d r}^{s} \quad, \quad \lambda_{q s}^{s}=L_{q s} i_{q s}^{s}+M_{q} i_{q r}^{s} \\
& \lambda_{d r}^{s} \quad M_{d} i_{a s}^{s}+L_{r} i_{d r}^{s} \quad, \quad \lambda_{q r}^{s} \quad M_{q} i_{q s}^{s}+L_{r} i_{q r}^{s} \\
& \tau_{e}=\frac{\text { Pole }}{2}\left(M_{q} i_{q s}^{5} i_{d r}^{5} \quad M_{d} i_{d s}^{5} i_{q r}^{5}\right) \\
& \frac{\text { Pole }}{2}\left(\tau_{\theta} \quad \tau_{l}\right)=J \frac{d \omega_{r}}{d t} \mid F \omega_{r}
\end{aligned}
$$

In (1), $v_{d s}^{s}, v_{q s}^{s}$ are the stator d-q axes voltages $i_{d s}^{s}, i_{q s}^{s}$ are the stator d-q axes currents $i_{d r}^{s}, i_{q r}^{s}$ are the rotor d-q axes currents $\lambda_{d s}^{s}, \lambda_{q s}^{s}$ are the stator d-q axes fluxes and $\lambda_{d r}^{s}, \lambda_{q r}^{s}$ are the rotor d-q axes fluxes. $r_{d s}, r_{q s}$ and $r_{r}$ denote the stator and rotor d-q axes resistances. $L_{d s}, L_{q s}, L_{r}, M_{d}$ and $M_{q}$ indicate the stator, the rotor self and mutual inductances. $\omega_{r}$ is the motor speed. $\tau_{e}$ and $\tau_{l}$ are electromagnetic torque and load torque respectively. Moreover, $J$ and $F$ are the moment of inertia and viscous friction coefficient, respectively. As can be seen from (1), the structure of SPIM equations is similar to the 3-phase IM equations. In fact, by substituting $r_{d s}=r_{q s}=r_{s}, L_{d s}=L_{q s}=L_{s}$ and $M_{d}=M_{q}=M$ the familiar equations of 3-phase IM are obtained.

\section{RFOC EQUATIONS OF SPIM}

Since the SPIM studied is asymmetrical, the use of conventional FOC method for 3-phase IM requires a special attention. This asymmetry in SPIM model causes oscillations in the SPIM electromagnetic torque [5]. In this paper, it is shown using an appropriate TM for stator current variables, this asymmetry can be removed. The electromagnetic torque of SPIM can be written as: 
$\tau_{e}=\frac{\text { Pole }}{2}\left(M_{q} i_{q s} i_{d r}-M_{d} i_{d s} i_{q r}\right)$

Using following substitutions,

$$
\begin{aligned}
& i_{D S}=i_{d s}-j i_{q s} \\
& i_{Q S}=j \frac{M_{d}}{M_{q}} i_{d s}+\frac{M_{d}}{M_{q}} i_{q s}
\end{aligned}
$$

The electromagnetic torque equation can be written as equation (4).

$$
\tau_{e}=\frac{\text { Pole }}{2}\left(M_{d} i_{Q S} i_{d r}-M_{d} i_{D S} i_{q r}\right)
$$

As can be seen from (4), the SPIM torque equation becomes similar 3-phase IM torque equation. Equation (3) can be written as:

$$
\left[\begin{array}{l}
i_{D S} \\
i_{Q S}
\end{array}\right]=\left[\begin{array}{cc}
1 & -j \\
j \frac{M_{d}}{M_{q}} & \frac{M_{d}}{M_{q}}
\end{array}\right]\left[\begin{array}{l}
i_{d s} \\
i_{q s}
\end{array}\right]
$$

Using following substitutions,

$$
\begin{array}{cc}
1 \rightarrow \cos \theta_{e} & j \rightarrow \sin \theta_{e} \\
i_{D S} \rightarrow i_{d s}^{s} & i_{d s} \rightarrow i_{d s}^{e} \\
i_{Q S} \rightarrow i_{q s}^{s} & i_{q s} \rightarrow i_{q s}^{e}
\end{array}
$$

The TM for stator current variables can be obtained as equation (7).

$$
\left[\begin{array}{l}
i_{d s}^{s} \\
i_{q s}^{s}
\end{array}\right]=\left[\begin{array}{cc}
\cos \theta_{e} & -\sin \theta_{e} \\
\frac{M_{d}}{M_{q}} \sin \theta_{e} & \frac{M_{d}}{M_{q}} \cos \theta_{e}
\end{array}\right]\left[\begin{array}{l}
i_{d s}^{e} \\
i_{q s}^{e}
\end{array}\right]
$$

The inverse of (7) gives the proposed TM for stator current variables.

$$
\left[\begin{array}{c}
i_{d s}^{e} \\
i_{q s}^{e}
\end{array}\right]=\left[T_{i s}^{e}\right]\left[\begin{array}{c}
i_{d s}^{s} \\
i_{q s}^{s}
\end{array}\right]=\left[\begin{array}{ll}
\cos \theta_{e} & \frac{M_{q}}{M_{d}} \sin \theta_{e} \\
-\sin \theta_{e} & \frac{M_{q}}{M_{d}} \cos \theta_{e}
\end{array}\right]\left[\begin{array}{l}
i_{d s}^{s} \\
i_{q s}^{s}
\end{array}\right]
$$

In (8), $\theta_{e}$ is the angle between the stationary reference frame and the rotating reference frame. In this paper superscript " $e$ " indicates that the variables are in the rotating reference frame. Using (8) new mathematical model is obtained as (9)-(11). It can be noted that in the process of obtaining these equations (equations (9)-(11)) the assumption $\lambda_{d r}^{e}=\left|\lambda_{r}\right|, \lambda_{q r}^{e}=0$ is considered.

Rotor flux equations:

$$
\begin{aligned}
& {\left[\begin{array}{c}
\left|\lambda_{r}\right| \\
0
\end{array}\right]=\left[\begin{array}{cc}
M_{d} & 0 \\
0 & M_{d}
\end{array}\right]\left[\begin{array}{c}
i_{d s}^{e} \\
i_{q s}^{e}
\end{array}\right]+\left[\begin{array}{cc}
L_{r} & 0 \\
0 & L_{r}
\end{array}\right]\left[\begin{array}{c}
i_{d r}^{e} \\
i_{q r}^{e}
\end{array}\right]} \\
& T_{r} \frac{d}{d t}\left|\lambda_{r}\right|+\left|\lambda_{r}\right|-M_{d} i_{d s}^{e}=0
\end{aligned}
$$


Electromagnetic torque equation:

$$
\tau_{e}=\frac{\text { Pole }}{2} \frac{M_{d}}{L_{r}}\left|\lambda_{r}\right| i_{q s}^{e}
$$

Speed equation:

$$
T_{r}\left(\omega_{e}-\omega_{r}\right)\left|\lambda_{r}\right|-M_{d} i_{q s}^{e}=0
$$

In (9) $T_{r}$ is the rotor time constant $\left(T_{r}=L_{r} / r_{r}\right)$. As can be seen using (8), the asymmetrical equations of SPIM changed into symmetrical equations. The comparison between the RFOC equations of SPIM and RFOC equations of 3-phase IM is given in Table 1.

\begin{tabular}{|c|c|c|}
\hline & 3-Phase IM & SPIM \\
\hline Flux equation based on [22], (9) & $\begin{array}{c}\left|\lambda_{r}\right|=\frac{M i_{d s}^{e}}{1+T_{r} \frac{d}{d t}} \\
\text { where: } \\
M=\frac{3}{2} L_{m s}\end{array}$ & $\begin{array}{c}\left|\lambda_{r}\right|=\frac{M_{d} i_{d s}^{e}}{1+T_{r} \frac{d}{d t}} \\
\text { where: } \\
M_{d}=\frac{3}{2} L_{m s}\end{array}$ \\
\hline Torque equation based on [22], (10) & $\tau_{e}=\frac{\text { Pole }}{2} \frac{M}{L_{r}}\left|\lambda_{r}\right| i_{q s}^{e}$ & $\tau_{e}=\frac{\text { Pole }}{2} \frac{M_{d}}{L_{r}}\left|\lambda_{r}\right| i_{q s}^{e}$ \\
\hline Speed equation based on [22], (11) & $\omega_{e}=\omega_{r}+\frac{M i_{q s}^{e}}{T_{r}\left|\lambda_{r}\right|}$ & $\omega_{e}=\omega_{r}+\frac{M_{d} i_{q s}^{e}}{T_{r}\left|\lambda_{r}\right|}$ \\
\hline
\end{tabular}

Table 1. The comparison between RFOC equations of SPIM and RFOC equations of 3-phase IM

Therefore, using some changes in the conventional RFOC block diagram of 3-phase IM, vector control of SPIM is possible. The proposed block diagram of SPIM based on Indirect RFOC is shown in Figure 2. In Figure 2, $\left|\lambda_{r}{ }^{*}\right|$ and $\tau_{e}{ }^{*}$ represent the reference flux and torque respectively. In this Figure, the arrows show that the changes to the conventional vector control, that it can be applied to the SPIM. In summery the comparison between the proposed vector control of SPIM and conventional vector control of 3phase IM is given in Table 2.

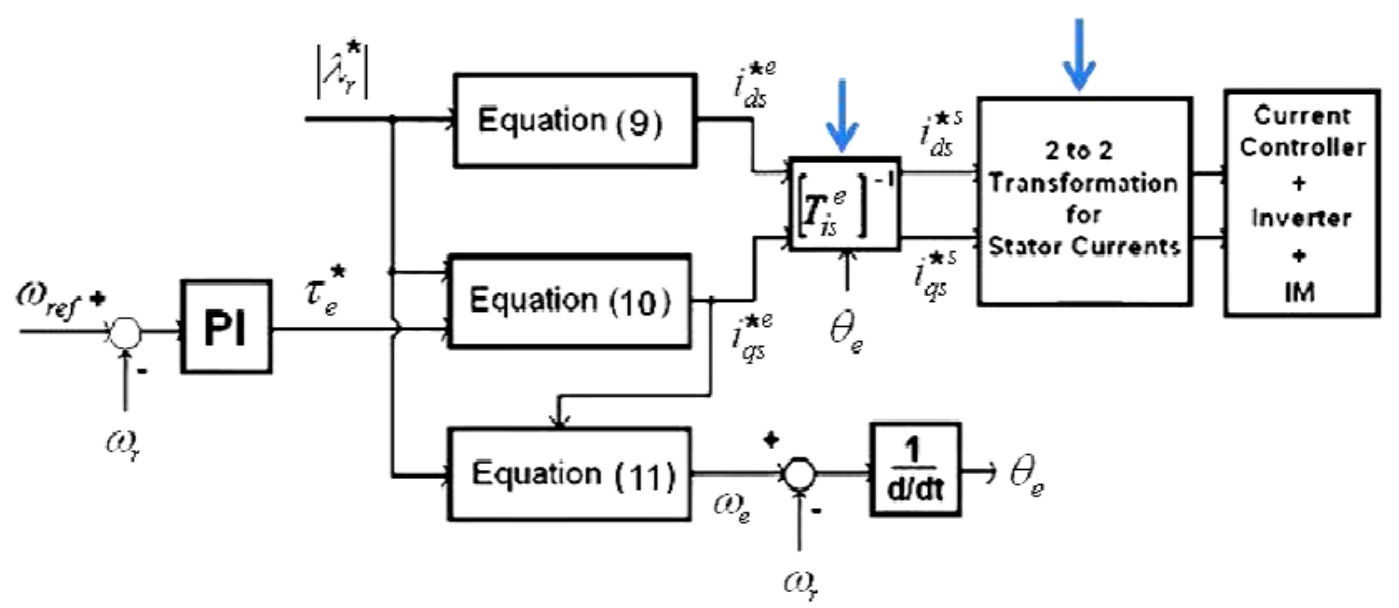

Figure 2. Proposed block diagram of IRFOC for SPIM 
Table 2. The comparison between proposed vector control of SPIM and conventional vector control of 3phase IM

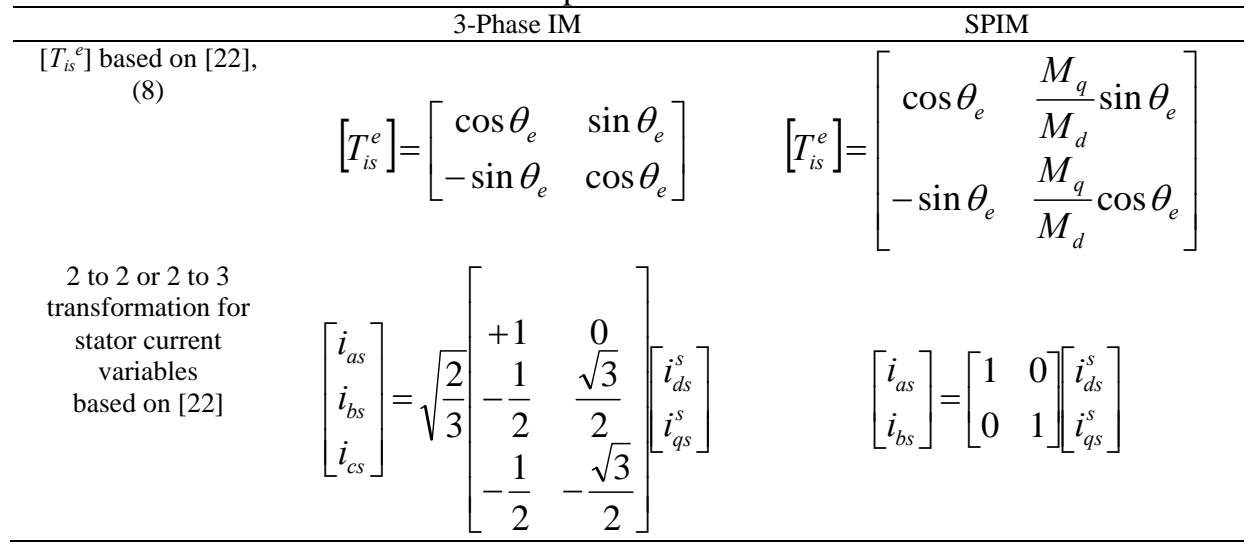

\section{SIMULATION RESULTS}

To verify the effectiveness of the proposed IRFOC for SPIM, simulations under different conditions are conducted using MATLAB/SIMULINK simulation package. In the simulations the reference rotor flux is set to $1 \mathrm{wb}$. A vector control system, based on Figure 2 is used for a standard 0.25 HP SPIM with the rated values and parameters as shown in Table 3.

Table 3. Ratings and parameters of the simulated SPIM

\begin{tabular}{|c|c|}
\hline Voltage & $90 \mathrm{~V}$ \\
\hline Frequency $(f)$ & $60 \mathrm{~Hz}$ \\
\hline No. of Polcs & 4 \\
\hline Power & $0.25 \mathrm{IIp}$ \\
\hline$r_{d s}$ & $7.14 \Omega$ \\
\hline$r_{q s}$ & $2.02 \Omega$ \\
\hline$M_{q}$ & $0.1772 \mathrm{H}$ \\
\hline$r_{r}$ & $4.12 \Omega$ \\
\hline$I_{d s}$ & $0.1885 \mathrm{H}$ \\
\hline$I_{q g}$ & $0.1844 \mathrm{H}$ \\
\hline$J$ & $0.0146 \mathrm{~kg} . \mathrm{m}^{2}$ \\
\hline$F$ & $0.0 \mathrm{~N} . \mathrm{m} . \mathrm{s}$ \\
\hline
\end{tabular}

Figure 3 (a) shows the simulation results of the reference and actual rotor speed based on proposed controller for a trapezoidal speed reference between 500rpm and -500rpm. It is evident from Figure 3 (a) that the real speed follows the reference motor speed even at zero reference speed. The electromagnetic torque and main and auxiliary stator currents for trapezoidal reference speed are shown in Figure 3 (b) and Figure 3 (c) respectively. It is shown that the proposed IRFO controller for vector control of SPIM has a good speed control and sufficient vector control characteristics. 


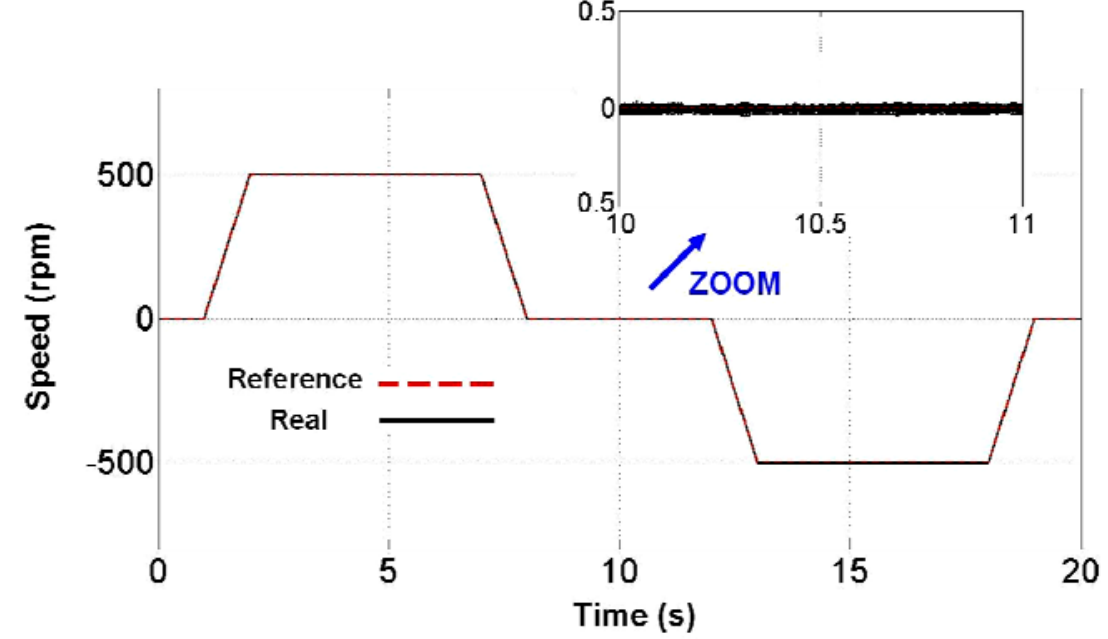

(a)

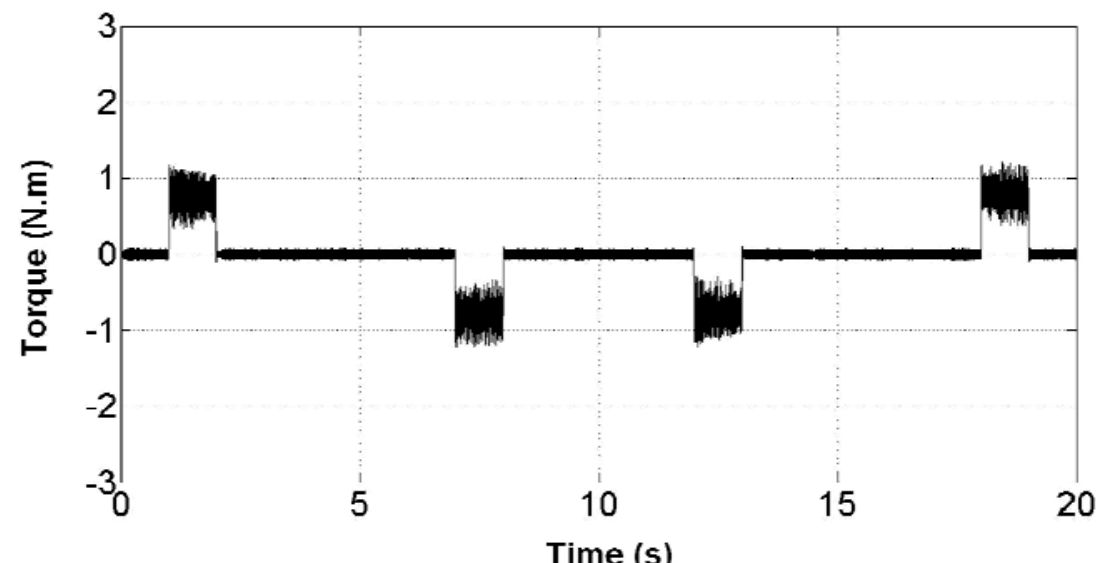

(b)

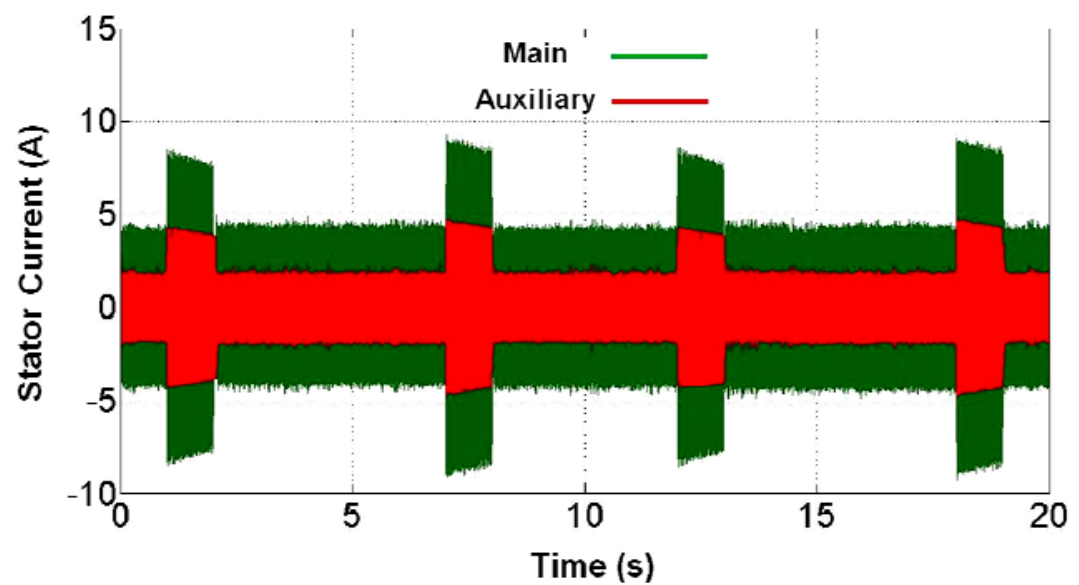

(c)

Figure 3. Simulation results of IRFOC for a trapezoidal reference speed

Figure 4 (a) shows the reference and real motor speed signals with a step reference speed from zero to the rated value at $\mathrm{t}=2 \mathrm{~s}$. A load torque equal to $1 \mathrm{Nm}$ is introduced at $\mathrm{t}=9 \mathrm{~s}$ and removed at $\mathrm{t}=11 \mathrm{~s}$. Due to the accuracy of the torque control, the actual speed follows the reference even when a load disturbance is introduced at $\mathrm{t}=2 \mathrm{~s}$. The corresponding motor torque is shown in Figure 4 (b). It can be seen that the torque response rapidly with no pulsations. 


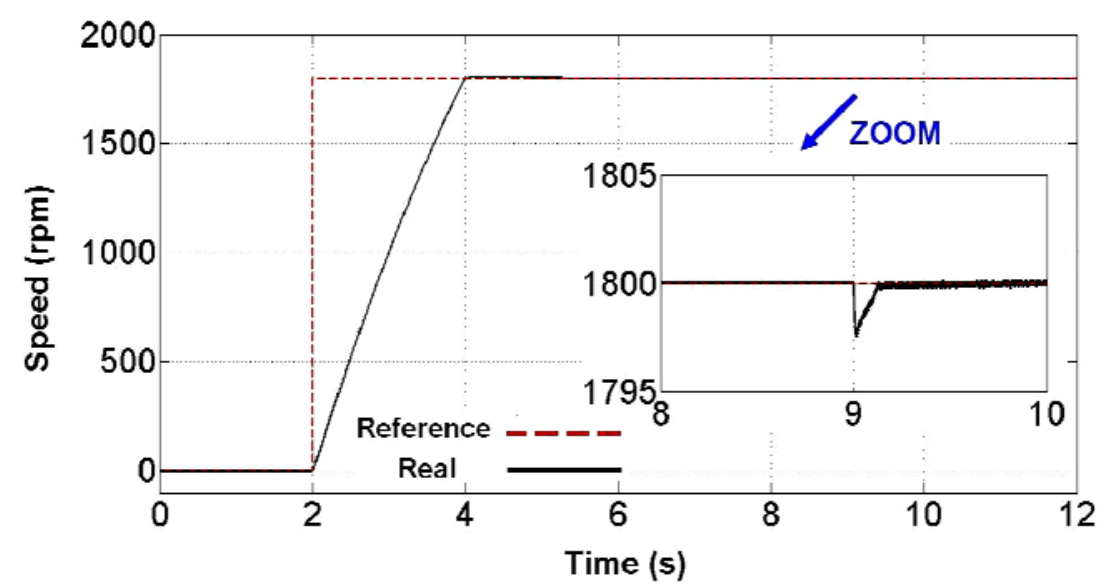

(a)

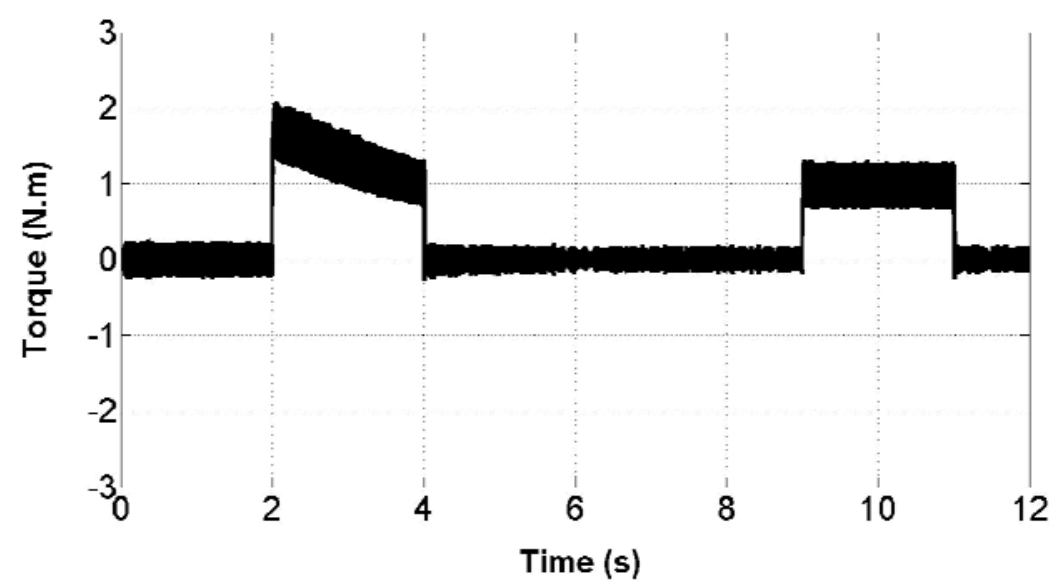

(b)

Figure 4. Simulation results of IRFOC at nominal reference speed and under load

\section{CONCLUSION}

In this paper, a novel method for speed control of SPIM based on IRFOC has been proposed. It is shown that using an appropriate transformation matrix (TM) for stator current variables, the unbalanced SPIM equations can be changed into balanced equations. Simulation results showed the excellence speed and torque responses obtained using the proposed technique. The drawback of presented method is that the motor speed of SPIM must be measured, which needs a speed sensor. To overcome this difficulty, a research to be conducted applying a novel method for speed sensorless FOC of SPIM.

\section{REFERENCES}

[1] F. Blaabjerg, et al. "Two-phase induction motor drives". IEEE Trans. Ind. Appl. Mag. vol. 10, pp. 24-32, Jul./Aug. 2004.

[2] M. Chomat and T.A. Lipo. "Adjustable-speed single-phase IM drive with reduced number of switches". IEEE Trans. Ind. Appl. vol. 39, pp. 819-825, May/Jun. 2003.

[3] M. Jemli, et al. "Sensorless Indirect Stator Field Orientation Speed Control for Single-Phase Induction Motor Drive". IEEE Trans. Power Electron. vol. 24, pp. 1618-1627, Jun. 2009.

[4] M.R. Correa, et al. "Rotor-flux-oriented control of a single-phase induction motor drive". IEEE Trans. Ind. Electron. vol. 47, pp. 832-841, Aug. 2000.

[5] M.B. de Rossiter Corrêa, et al. "Vector control strategies for single-phase induction motor drive systems". IEEE Transactions on Industrial Electronics. vol. 51, pp. 1073-1080, 2004.

[6] N.M. Abdel-Rahim and A. Shaltout. "An asymmetrical two-phase induction motor drive with slip-frequency control". IEEE Transactions on Energy Conversion. vol. 24, pp. 608-616, 2009.

[7] W. Piyarat, et al. "Simple speed control of an asymmetrical type two-phase induction motor drive". In Electrical Engineering/Electronics Computer Telecommunications and Information Technology (ECTI-CON). pp. 274-278, 2010. 
[8] B. Zahedi and S. Vaez-Zadeh. "Efficiency optimization control of single-phase induction motor drives". IEEE Transactions on Power Electronics. vol. 24, pp. 1062-1070, 2009.

[9] V.S. Fating, et al. "Direct torque control of symmetrical and asymmetrical single phase induction motor". In Power System Technology and IEEE Power India Conference. pp. 1-4, 2008.

[10] F.A. Neves, et al. "Single-phase induction motor drives with direct torque control". In 28th Annual Conference of the Industrial Electronics Society. pp. 241-246, 2002.

[11] S. Reicy and S. Vaez-Zadeh. "Vector control of single-phase induction machine with maximum torque operation". In Proceedings of the IEEE International Symposium on Industrial Electronics, ISIE 2005. pp. 923-928, 2005.

[12] H. Ben Azza, et al. "Full-Digital Implementation of ISFOC for Single-Phase Induction Motor Drive Using dSpace DS 1104 Control Board". International Review of Electrical Engineering. vol. 3, pp. 721-729, 2008.

[13] M. Jemli, et al. "Real-time implementation of IRFOC for single-phase induction motor drive using dSpace DS 1104 control board". Simulation Modelling Practice and Theory. vol. 17, pp. 1071-1080, 2009.

[14] H.B. Azza, et al. "High performance sensorless speed vector control of SPIM Drives with on-line stator resistance estimation". J. Simulat. Practice Theory. vol. 19, pp. 271-282, 2011.

[15] H.B. Azza, et al. "Implementation of Sensorlee Speed Control for Two-Phase Induction Motor Drive Using ISFOC Strategy". Transactions of Electrical Engineering. vol. 35, pp. 63-74, Jun. 2011.

[16] M. Jannati, et al. "Speed Sensorless Direct Rotor Field-Oriented Control of Single-Phase Induction Motor Using Extended Kalman Filter". International Journal of Power Electronics and Drive Systems (IJPEDS). vol. 4, pp. 430438, 2014.

[17] M. Jannati, et al. "A Novel Scheme for Reduction of Torque and Speed Ripple in Rotor Field Oriented Control of Single Phase Induction Motor Based on Rotational Transformations". Research Journal of Applied Sciences, Engineering and Technology. vol. 7, pp. 3405-3409, 2014.

[18] M. Jannati, et al. "A Novel Technique for Vector Control of Single-Phase Induction Motors Based on Rotor FieldOriented Control". TELKOMNIKA Indonesian Journal of Electrical Engineering. vol. 12, pp. 8104-8113, 2014.

[19] M. Jannati, et al. "An Exact Model for Rotor Field-Oriented Control of Single-Phase Induction Motors". TELKOMNIKA Indonesian Journal of Electrical Engineering. vol. 12, pp. 5110-5120, 2014.

[20] M. Jannati, et al. "A new method for RFOC of single-phase induction motor based on rotational transformations". In 2013 IEEE Student Conference on Research and Development (SCOReD). pp. 215-220, 2013.

[21] D.H. Jang. "Problems Incurred in a Vector-Controlled Single-Phase Induction Motor, and a Proposal for a VectorControlled Two-Phase Induction Motor as a Replacement". IEEE Trans. Power Electron. vol. 28, pp. 526-536, Jan. 2013.

[22] P. Vas. "Vector Control of AC Machines". Oxford science publication. 1990. 